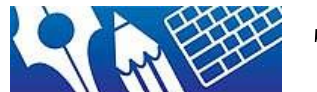

Australasian Association of Writing Programs

\section{TEXT SPECIAL ISSUES}

Number 65 October 2021

ISSN: 1327-9556 | https://textjournal.scholasticahq.com/

'Dancing about architecture': the fraught practice and chequered history of writing about the physical act of wave riding

\title{
Tim Baker
}

To cite this article: Baker, T. (2021). 'Dancing about architecture': the fraught practice and chequered history of writing about the physical act of wave riding. In Nigel Krauth, Sally Breen, Tim Baker and Jake Sandtner (Eds.) Creative writing and surfing. TEXT Special Issue 65. https://doi.org/10.52086/001c. 28112 


\title{
Griffith University
}

\author{
Tim Baker
}

\section{'Dancing about architecture': the fraught practice and chequered history of writing about the physical act of wave riding}

\begin{abstract}
$\underline{\text { Abstract: }}$
It has been said of music journalism, that writing about music is like dancing about architecture, a flawed and pointless exercise, the wrong medium for the artform. One might regard surf writing similarly. Perhaps the point of surf writing is that the experience is so fleeting and elusive that attempting to convey it in literary form stretches any writer to their limits. It is an open-ended challenge in which we are almost destined to fail but compelled to try anyway, like paddling out in a tumultuous sea, or taking off on a close-out.

This paper provides an historic overview of literary efforts to conjure the ethereal, multi-sensory experience of wave-riding, not just surf writing in general, but specifically efforts to describe the physical act of wave riding. I have written about surfing, as a career, for over 35 years, and am often struck by how little surf writing is focussed on describing the act itself. Most surf writing concerns itself with character profiles of elite surfers, exotic travel, competition, social and environmental issues that impact surfing. In the context of the popular surf media, images are the hero, better able to capture the splendour and magic of wave-riding, where words may seem inadequate.
\end{abstract}

\section{Biographical note:}

Tim Baker is an award-winning author, journalist and storyteller specializing in surfing history and culture, working across a wide variety of media from books and magazines to film, video, and theatre. Tim is the best-selling author of numerous books on surfing. Occy was a national bestseller and chosen by the Australia Council as one of '50 Books You can't Put Down' in 2008. Surfari tells the story of his family surfing road trip around Australia in 2011. Century of Surf, a history of Australian surfing, was published by Random House in 2013. His children's book The Surfer and the Mermaid was adapted for theatre for the Bleach Festival. His latest book The Rip Curl Story documents the rise of the iconic Australian surf brand to mark its 50th anniversary in 2019. Tim is a former editor of Tracks and Surfing Life magazines. He has won the 
Surfing Australia Hall of Fame Culture Award three times. He is currently completing a creative writing $\mathrm{PhD}$ at Griffith University.

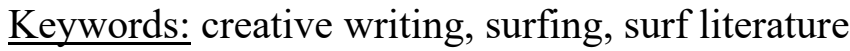

Surfing is an activity unique in the world - the only sport in which the participant is riding a moving vehicle, the surfboard, which itself is travelling on a moving medium, the wave. Unless you try to snowboard an avalanche, or rally drive in an earthquake. The complex biomechanics and hydrodynamics of surfing make it difficult to describe, especially to the non-surfer. The wave, surfer and surfboard engage in a chaotic though sometimes graceful dance, propelled by the upward thrust of the ocean swell and the downward pull of gravity.

This paper provides an historic overview of literary efforts to conjure the ethereal, multisensory experience of wave-riding, not just surf writing in general, but specifically efforts to describe the physical act of wave riding. I have written about surfing, as a career, for over 35 years, and am often struck by how little surf writing is focussed on describing the act itself. Most surf writing concerns itself with character profiles of elite surfers, exotic travel, competition, social and environmental issues that impact surfing. In the context of the popular surf media, images are the hero, better able to capture the splendour and magic of wave-riding, where words may seem inadequate.

Having read, written and reviewed a large cross-section of surf literature, from magazines to memoirs, historical accounts to fiction, my focus here is on those generally brief passages that home in on the act itself, to see how writers of different eras and backgrounds have attempted to convey the soaring, sensory drama and spectacle of riding waves.

My explorations will take us time-travelling from ancient Polynesian chants and myths to early European explorers, encounters with Hawaiian wave-riding by literary giants such as Jack London and Mark Twain, through the acid-infused ramblings of the counter-culture surfers of the late ' 60 s and early ' 70 s, to celebrated contemporary writers such as Tim Winton, Fiona Capp, Susan Carey and William Finnegan and the wildly varied offerings of the surf media.

But can writing ever truly capture the surfing experience? Like an active form of meditation, the conscious, intellectual mind is not engaged while surfing. The surfer acts on pure instinct and intuition, reading the ever-changing contours of the breaking wave, and so the intellectual mind struggles to summon up the experience in the re-telling, as if trying to conjure a dream.

It has been said of music journalism, that 'writing about music is like dancing about architecture' (Quote Investigator, 2010), a flawed and pointless exercise, the wrong medium for the artform. One might regard surf writing similarly. Perhaps the point of surf writing is that the experience is so fleeting and elusive that attempting to convey it in literary form stretches any writer to their limits. It is an open-ended challenge in which we are almost destined to fail but compelled to try anyway, like paddling out in a tumultuous sea, or taking off on a close-out. 
The earliest accounts of surfing are written records of an oral storytelling tradition, in the forms of Polynesian myths and chants that have been documented and interpreted by European historians or, in some cases, Polynesian academics. It is likely that some nuances may be lost in translation, across cultures and over time. To the modern reader, these accounts seem to skew heavily to an almost erotic view of the surfing act, though whether this reflects the Polynesian view of wave riding at the time, or a cultural bias of its documenters is difficult to discern. Either way, there are many references to loin cloths flying in the wind and suggestions that boasts of surfing prowess, like the braggadocio of modern-day rappers, infer some sort of sexual potency or proficiency, for example:

O ka papa he'e nalu keia, pahe'e I ka nalu ha'i o Makaiwa

'This is the surfboard that will glide on the rolling surf of Makaiwa.' (Pukui, 2008, p. 48)

In 1983, Hawaiian scholar Mary Kawena Pukui provided the following interpretation: 'A woman's boast. Her beautiful body is like the surfboard on which her mate "glides over the rolling surf"' (p. 48).

Allegories using birds and wings are also commonplace in both ancient Hawaiian and modern western descriptions of surfing. Indeed, flying might be the most common metaphor across all forms of surf writing.

My board mounts the crest

My loincloth flies in the spray of the sea

I am like the iwa bird crying wildly

As it soars so high above (Traditional song qtd in Baker, 2005, p. IX)

Surfing in ancient Hawaii is frequently dubbed 'the Sport of Kings' and chants and myths of the time often refer to contests between rival kings or chiefs. Each had their attendant surf chanter to describe their rides, so it was difficult to tell if these were contests of sport or oratory, like surf commentators pumping up a local favourite, or an oceanic rap battle.

The Journal of the Polynesian Society records the story of Naihe, the champion surfer of Kau, whose surfing prowess made other chiefs so jealous they plotted to trick him into a surfing match at Hilo and leave him stranded out at sea. Unbeknown to Naihe, a rule of the contest stated surfers couldn't return to shore until their surf chanter recited their special surf chant. According to legend, Naihe had been accompanied by his surf chanter, an elderly woman, and both were unaware of the rule. He had allowed her to sleep while he surfed and thus was prohibited from returning to shore. A chief from Puna took pity on Naihe and sent a servant to awaken the old woman who then performed her chant, releasing Naihe from his watery confinement.

Part of this chant, as translated by Mary Pukui, reads:

The great waves, the great waves rise in Kona, Bring forth the loin cloth that it might be on display. 
The ebbing tide swells to set the loin cloth flying, The loin cloth, Hoaka, that is worn on the beach, It is a loin cloth to wear at sea, a chief's loin cloth. Stand up and gird on the loin cloth.

The day is a rough one befitting Naihe's surf board.

He leaps in, he swims, he strikes out to the waves,

Waves that break into a heap, waves that break and spread.

The surf that rises above them all,

The rough surf on the island,

The great surf that pounds and thrashes... (Finney, 1959, pp. 327-347)

Surfing was so familiar to the ancient Hawaiians it did not require vivid physical description, yet for early Europeans the spectacle was almost beyond comprehension, and they had no cultural or sporting reference points to compare it to. The following descriptions are concerned with attempts to convey the mechanics of the exercise and include little in the way of vivid or poetic description. They might be considered anthropological exercises, as in this account from Lt. James King in A Voyage to The Pacific (1777):

Twenty or thirty of the natives, taking each a long narrow board, rounded at the ends, set out together from the shore. The first wave they meet they plunge under, suffering it to roll over them, rise again beyond it, and make the best of their way, by swimming out into the sea... As soon as they have gained by these repeated efforts, the smooth water beyond the surf, they lay themselves at length on their board, and prepare for their return. As the surf consists of a number of waves, of which every third is remarked to be always much larger than the others, and to flow higher on the shore, the rest breaking in the intermediate space, their first object is to place themselves on the summit of the largest surge, by which they are driven along with amazing rapidity toward the shore. (King in Cook, 1784, pp. 145-7)

Inevitably, the writing of the time, like the etchings of early European artists, falls short of capturing the experience so that the audience might be left little illuminated as to its true nature, and often includes outright inaccuracies (Who knew the third wave in a set was always larger than the rest?).

Other cultural biases reveal themselves in these early European records of surfing. Also from A Voyage to the Pacific (1784), naturalist William J. Anderson observes a canoe surfer in Tahiti but initially assumes his focus and paddling speed are signs that he has committed some act of thievery from the visiting European sailors, rather than a simple case of 'surf stoke'.

I saw a man paddling in a small canoe so quickly and looking about with such eagerness, on each side, as to command my attention. At first, I imagined that he had stolen something from one of the ships, and was pursued; but, on waiting patiently, saw him repeat his amusement. He went out from the shore, till he was near the place where the swell begins to take its rise; and watching its first motion very attentively, paddled before it with great quickness, till he found it overtook him, and had acquired sufficient 
force to carry his canoe before it without passing underneath. He then sat motionless, and was carried along, at the same swift rate as the wave, till it landed him upon the beach. Then he started out, emptied his canoe, and went in search of another swell. I could not help concluding, that this man felt the most supreme pleasure, while he was driven on, so fast and so smoothly, by the sea. (Anderson in Cook, 1784, p. 405)

Equine metaphors are another common, if less obvious, device that appears in many historical accounts. To the modern eye it seems hard to discern in which ways a wave resembles a horse, though it is a descriptor that has endured, in everything from beer commercials to surfing magazine titles:

The girls at the outmost roller, when awaiting the moment before it breaks, they come flying in on the very crest of the wave, at speed of a race-horse, the great art being to preserve so nice a poise on the backbone, as it were, of the breaker, as not to be left behind, nor yet, as I found at the cost of several abrasions, launched too far ahead, and thus have the whole crash of the roller pitching you over and over in a series of hydropathic revolutions by no means safe or pleasant. (Wise, 1850, pp. 352-4)

The visitor at Hilo may enjoy the sport of surf-swimming if he does not mind being drowned in the attempt... The chief skill required for successful performance of this feat is keeping the head and shoulders just ahead and clear of the great cresting wave that rears itself high above and threatens every moment to bury the bold performer. In fact, he may be said, figuratively, to ride on the neck of the white charger while holding its mane. (Boddam-Whetman, 1876, pp. 118-20)

The first noted western writers to describe surfing, as opposed to European explorers obliged to keep journal entries, were the heavyweight literary triumvirate of Herman Melville, Mark Twain and Jack London, in the mid to late $19^{\text {th }}$ and early $20^{\text {th }}$ centuries. Though their writings span some 60 or so years, there is a common air of drama and familiar allegories amongst them. In 1849, Melville spares no superlatives nor metaphors in this breathless account:

...where the waves muster for the onset, thundering in water-bolts that shake the whole reef till its very spray trembles ... then is it the swimmers of Ohonoo most delight to gambol in the surf... Here, throwing themselves upon their boards, tranquilly they wait for a billow that suits. Snatching them up, it hurries them landward, volume and speed increasing till it races along a watery wall like the smooth, awful verge of Niagara. Hanging over this scroll, looking down from it as from a precipice, the bathers halloo, every limb in motion to preserve their place on the very crest of the wave. Should they fall behind, the squadrons that follow would whelm them; dismounted and thrown forward, as certainly would they be run over by the steed they ride. 'Tis like charging at the head of cavalry; you must on... At last, all is lost in scud and vapor as the overgrown billow bursts like a bomb. Adroitly emerging, the swimmers thread their way out and, like seals at the Orkneys, stand dripping upon the shore. (Melville, 1964, p. 239) 
To modern sensibilities, Twain and London use some uncomfortable racial references, though they reach very different conclusions about the faculty of the various races to learn to surf. While Twain conforms to a common trope that Polynesians possess some magical amphibian gene that makes them uniquely qualified for wave riding, London sees it as a test of manhood and pride for the visiting white man to rise to the challenge. Their accounts are notable too as some of the first examples of western surf writing by a participant and not just an observer. Writes Twain in 1872:

In one place we came upon a large company of naked natives, of both sexes and all ages, amusing themselves with the national pastime of surf bathing. Each heathen would paddle three or four hundred yards out to sea, (taking a short board with him), then face the shore and wait for a particularly prodigious billow to come along; at the right moment he would fling his board upon its foamy crest and himself upon the board, and here he would come whizzing by like a bombshell! It did not seem that a lightning express train could shoot along at a more hair-lifting speed. I tried surf-bathing once, subsequently but made a failure of it. I got the board placed right, and at the right moment too; but missed the connection myself. The board struck the shore in three quarters of a second, without any cargo, and I struck the bottom about the same time with a couple of barrels of water in me. None but natives ever master the art of surf bathing. (Twain, 1872, pp. 525-6)

London delivered perhaps the most evocative description to this point (i.e. 1907) with his gushing prose in The Cruise of the Snark (1907), where he appears in complete awe of the Hawaiian surfer.

Where but the moment before was only the wide desolation and invincible roar, is now a man, erect, full-statured, not struggling frantically in that wild movement, not buried and crushed and buffeted by those mighty monsters, but standing above them all, calm and superb, poised on the giddy summit, his feet buried in the churning foam, the salt smoke rising to his knees, and all the rest of him in the free air and flashing sunlight, and he is flying through the air, flying forward, flying fast as the surge on which he stands. He is Mercury, a brown Mercury. His heels are winged, and in them is the swiftness of the Sea. (London, 1907, p. 76)

But London's response to this spectacle is to see it as a matter of racial pride that he can learn to emulate; that the 'Kanaka' could not be capable of something that he, 'one of the kingly species', is not.

It is all very well, sitting here in the cool shade of the beach; but you are a man, one of the kingly species, and what that Kanaka can do you can do yourself. Go to. Strip off your clothes, that are a nuisance in this mellow clime. Get in and wrestle with the sea; wing your heels with the skill and power that reside in you; bit the sea's breakers, master them, and ride upon their backs as a king should. (London, 1907, p. 78) 
One of the first examples of Australian surf writing comes from a relatively obscure book, Manual of Swimming, published in 1867, by an English swimming champion, Charles Steedman, who emigrated to Australia in 1854. In an intriguing chapter titled, 'Native Swimming, wave mechanics and surfboards', (which predates the widely accepted introduction of surfing to Australia by Hawaiian champion Duke Kahanamoku in 1914 by almost 50 years), Steedman writes a vivid description of Aboriginals engaging in what sounds a lot like body surfing, a pastime not often associated with Indigenous Australians:

Extended in a line, they will stand to meet the incoming of the small seas, and will perform the most amusing feats, as the force of the breakers drives them back to shore. On the approach of a large wave the white man will usually dive and work their hands into the sand, so to obtain a firm hold as the sea bursts over them; while the blacks on the contrary will rise on the crest and continue to go through their eccentric and amusing evolutions as usual. (Steedman, 1867, p. 264)

But the true beginnings of surf writing in Australia are due to another swimming champion, Cecil Healy, who befriended the great Hawaiian surfer and swimmer Duke Kahanamoku at the 1912 Stockholm Olympics. Duke famously missed his 100 metres semi-final in Stockholm due to confusion over the scheduling and Healy refused to swim in the final until Duke, as the world record holder, was given a chance to qualify, contending that he did not want to win against a diminished field. Duke's semi was re-scheduled, he easily qualified for the final and edged Healy into second place. Healy's act of sportsmanship may have cost him a gold medal, but it cemented a firm friendship between the Australian and Hawaiian swimmers. Healy invited Duke to Australia and the Hawaiian gratefully agreed to a series of swimming meets and surfing exhibitions. Healy was also a part-time newspaper columnist, and his descriptions of Duke's surfing exhibitions are perhaps the first local examples of the genre, employing the bynow familiar equine metaphor:

On sighting a like-looking wave, he commenced to paddle vigorously, still lying prone as before. After a few ineffectual attempts he succeeded in catching one properly. Instantly the board seemed to leap forward like a fiery steed when the spurs are driven into the rowels. Immediately afterwards the Duke rose upright and assumed the attitude of ancient chariot drivers. And no sooner had he done so than he appeared to exercise some subtle influence over the madly careering craft: in fact, just as if he had taken the reins in hand, he altered its directions so as to steer a course diagonal to the beach. Although the prow pranced and bounded over the crest of the onrushing billow, the Duke stood like an ebony statue, immoveable save for the deft movements of his feet. (Healy, 1915, p. 1)

It may come as a surprise to many to learn that Australia's most prolific surf writer in the first half of the $20^{\text {th }}$ century was a woman, C. Bede Maxwell, whose pen name may have been fashioned to obscure her gender. She wrote the first definitive history of Australian surfing, Surf-Australians Against the Sea, published in 1949, and focussed squarely on the surf lifesaving movement, often conjuring a military metaphor to describe the exertions of surf club 
members to keep the ocean-going public safe. Her writing on surf boat and surfboard events in large surf, often viewed from a boat at sea, are a high point of the genre:

An excited visitor from overseas has described the spectacular engagement with the seas as "mountaineering in boats". "Mountaineering in boats it is!" she wrote of the popular surfboat races of the day. "It is a negotiation of eminences that rear and topple; that flatten and surge to involve all within their sphere of influence in their own crumbling ruin. Against such high-reared force is opposed only the strength of tough spruce oars, of the muscular men who wield them, of the buoyant, reinforced timbers of the well-built boats. On casual examination, advantage seems unduly to favour the sea". (Maxwell, 1949, p. 86)

Some of Maxwell's most arresting prose concerned the so-called Roman Holiday, an infamous surf club carnival staged in monster seas at Maroubra in 1947:

It had been something to see - the lone rider far out, tossed one moment to the crest of some terrifying wave, and the next thrust deep into troughs scooped out like Blue Mountains gullies. For incredible seconds of time, the lovely magpie board [the surfer Keith Hurst's board was painted with distinctive black and white stripes] had carried Hurst to the very crest of what has been estimated a 20-foot wave and he swayed there in a crazy, graceful, sea-saw motion, the hollow length evenly balanced across the wave, the accomplished rider in full control. When the wave, a mile-long liquid precipice fronting the beach, began to crumble, the spectators strained forward in their seats. If Hurst dared to take it, would he survive the down-dashing force? A catch of the breath that was almost a sob gave expression to the relief of most as they saw the magpie board slip back to safety and the wave go down without him. (p. 243)

Another highlight in Australian surf literature of the era came from another unexpected source, not just a woman, but a poet at that. Judith Wright's 'The Surfer' has become an Australian classic, studied by generations of literature students for its compelling evocation of the ocean environment and the surfer's dedication to it, verging on the erotic in a way that echoes the old Hawaiian chants. This passage from it also forms the inscription to Maxwell's book:

He thrust his joy against the weight of the sea;

Climbed through, slid under those long banks of foam -

(hawthorn hedges in spring, thorns in the face stinging).

How his brown strength drove through the hollow and coil

Of green-through weirs of water

Muscle of arm thrust down long muscle of water;

And swimming so, went out of sight

Where mortal, masterful, frail, the gulls went wheeling

In air as he in water, with delight (Wright, 1945, p. 4)

But not all, or even most, surf literature was so literary. The Gidget phenomenon of the $1950 \mathrm{~s}$, the popular novels and films depicting the Californian surfing lifestyle, spawned a wave 
(excuse the pun) of Hollywood teen beach movies and pulp fiction novels. In Australia, pulp author Ray Slattery pumped out dozens of such titles, the best known of which appear to be Surfari Highway (1965) and its sequel Wild Water (1966). While the plots and characters might be a little thin, the surfing sequences at least ring true, with a kind of innocent, unpretentious authenticity, and an understanding of the obsessive dedication of the committed surfer:

The wave gathered speed. Jonnie found himself too far down the face of it. He stepped back on his board and brought her nose up. The nose poked into space with a sheer fall below, and behind him the board cut a creaming vee in its wake. These were familiar moments that were always new and never quite the same, this was the thrill for which a surfer was prepared to chop six months out of his working life and travel a thousand miles. There were times when the idea disturbed him, even scared him. But the pull of the surf was there - stronger than his fears for the future. (Slattery, 1966, p. 51)

But things were about to get ... weird. And as Hunter S. Thompson put it, 'when the going gets weird, the weird turn pro' (Thompson, 2003, p. 530). It didn't take long for the Summer of Love, and its attendant long hair, flower power, and psycho-active drugs to migrate from the Haight Ashbury district of San Francisco and wash up on the beaches of Australia, most notably the northern beaches of Sydney and the north coast of NSW. You can get as cosmic as you like about the act of wave riding, which was very cosmic indeed for the first generation of counterculture surfers. The arrival of hallucinogens in the late 1960s coincided with the development of modern, more manoeuvrable shortboards, spawning a whole new surfing vocabulary.

Ringmaster of the so-called shortboard revolution Bob McTavish famously declared that surfing the long, air-brushed, peeling waves of Noosa Heads was like 'having a cup of tea with god' (McTavish, 1967, p. 9). Bob wrote some of the most garbled, drug-infused ravings of the times in magazine articles, attempting to evoke the ethereal wonders of what he dubbed the 'involvement school' of progressive surfing, with a kind of jazz-infused, free-form poetry that would make even the Beats blush.

'Mind, Body, Soul: Surfer, Board, Wave; Total and Complete Involvement. Let the mind unshackle, set it free. Let it stroll, run, leap, laugh in gardens of crystal motion and sun and reality,' Bob famously wrote in a 1967 edition of Surf International, in an article titled, 'Ladies and Gentlemen and Children of the Sun'. 'Talk with the caretaker on the Plastic Telephone. Weave and paint with the hand of your imagination, with the fingers of your body, the brush of fibreglass' (McTavish, 1967, p. 9). The surf media of the late '60s and early '70s was awash with these sorts of hippy, stream of consciousness raves and some truly appalling poetry. Waves were 'crystalline vortexes' and 'pressurised liquid rodeos'; the tube was 'womb-like' or a 'green cathedral' that led to a kind of 're-birth'.

By the time I entered the surf media in the mid-1980s, from a background in the bump and grind of daily newspapers, pro surfing had arrived, and surfers had well and truly turned against this kind of grandiose counter-cultural posturing. The pervading ethos was to 'rip, tear and lacerate' the wave, the surfer's individual egoism over-riding a previous generation's awe and wonder at the natural world. 
As a surf magazine editor, I always considered the photos to be the stars of the show, that could convey the majesty and spectacle of surfing and the ocean environment far better than the clumsy prose of your average surf writer. When I look back over my own body of work there are precious few examples of describing actual wave-riding. But just occasionally, and when writing for a mainstream audience unfamiliar with the dynamics of surfing, I felt like I stumbled onto some sort of truth. The following scene burned such an indelible impression on my consciousness, even nearly 25 years later, I hope I managed to convey something of the spectacle accurately.

'It's dawn at Snapper Rocks, at the southern end of the Gold Coast, where an exquisite buildup of sand has coincided with the first cyclone swell of the year,' I wrote in a profile of re-born surfing hero Mark Occhilupo for Inside Sport magazine in April, 1997:

The sun is barely above the horizon when I pull up into the car park, just as a familiar figure races along the base of a towering wave. Occy compresses through a low-centred bottom turn, drives vertically up the face of the wave and tears a devastating gouge through the cresting peak. He flies out of the top of the wave - for one impossible instant, I swear, completely upside down, clawing the wave face and raking his board through the lip - then drives back down the face and into the next bottom turn. (Baker, 1997, page numbers unavailable)

If there's one thing I've learned from 35 years of surf writing and editing, it is that great surf writing does not need to be about great or elite surfing moments. One of my favourite pieces of surf writing is by an adult woman, Fiona Capp, attempting to re-learn to surf after a 20-year absence from the waves, after career and motherhood interrupted her wave-riding adventure. This fraught process is wonderfully captured in her memoir That Oceanic Feeling and her gentle description of one successful ride in knee-high surf is as powerfully rendered as any big wave or surf-star histrionics:

I could almost hear a click as everything slipped into place... Everything felt strangely effortless as the wave picked me up and I rose to my feet. From then on, it was as if a spell had been cast over the water, the waves unspooling like liquid celluloid as I floated across their flickering walls, grinning with disbelief. I'd never experienced anything like this before ... marvelling at the way the wave itself seemed to guide me in these basic steps, like a parent taking a child's hand. How simple and clear it all suddenly seemed. This was how it was supposed to be. This was what it was all about... I knew I had to hang on to this sensation of discovery, this joy of learning how to walk again. When I paddled back to the lineup, all the other surfers seemed to be smiling at me perhaps because I was now smiling at them. (Capp, 2003, p. 86)

Contemporary, literary surf writing has an unexpectedly broad canon with an impressive cast of writers applying their powers to evoking the wonder of that oceanic feeling - Daniel Duane, Tim Winton, Kem Nunn, Susan Carey, William Finnegan, Malcolm Knox. The experiences that surfers have in the ocean are so dynamic, literally so fluid, that it is a test of any writer's vocabulary and literary bag of tricks to evoke it convincingly and compellingly. Perhaps only 
erotica walks a similarly fine line between the sublime and the ridiculous. And like erotica, if the writing is seen as some desperate surrogate for engaging in the physical activity itself, the only thing aroused are the readers' suspicions.

My conviction that photos could convey surfing better than words was shaken when I was sent an early manuscript of Tim Winton's Breath. A lifelong surfer and ocean lover, it had taken Winton more than 20 years to get around to writing a surfing novel, he says because he feared the stigma of being labelled a 'surfing writer', that he had to earn his literary chops before he dared indulge his personal obsession in literary form. I stayed up late into the night reading that loose leaf manuscript in one sitting, equal parts dismayed and inspired that the essence of the surfing act could be conveyed in words this successfully, all while noting some echoes of London or Melville in the following:

In a moment the wave was upon me, its mass overtaking me so fast that it felt as though I was travelling backwards. All about me was seething vapour. I hung right up there in the boiling nest of foam at its very peak, suspended in noise and unbelief, before I began to fall out and down in a welter of blinding spray. I only got to my feet from instinct, but there I suddenly was, upright and alive, skittering in front of all that jawing mess with my little board chattering underfoot. It was hard to credit the speed, the way the wave hauled itself upright in my path as it found shallower water. All I could do was squat and aim in hope. Yet for all that mad acceleration there was still something ponderous about the movement of the water. On TV I'd seen elephants run beside safari jeeps, pounding along at incredible speed while seeming to move in slow motion, and that's exactly how it was: hectic noise, immense force driven up through the feet and knees, all in a kind of stoptime... I never did see the great slab of water that cut me off at the knees. Loonie said it came down behind like a landslip and simply flicked me away. I didn't even get time to draw a breath. I was abruptly in darkness, being poleaxed across the sandy bottom of the bay, holding on to the dregs in my lungs while the grit blasted through my hair and my limbs felt as though they would be wrenched from my sockets. (Winton, 2008, pp. 48-49)

Winton also touches on one of the key appeals of surfing and surf writing that is rarely articulated when his protagonist first encounters wave-riding: 'I couldn't have put words to it as a boy, but later I understood what seized my imagination that day. How strange it was to see men do something beautiful. Something pointless and elegant, as though nobody saw or cared' (Winton 2008, p. 23).

When William Finnegan's surfing memoir Barbarian Days won the 2016 Pulitzer Prize for Literature it seemed surf writing was finally having its moment, no longer something to be embarrassed about; a passion for surfing and a desire to describe the mad, transcendental experiences the ocean delivers, a guilty secret no more. But perhaps in defiance of my original topic, one of the most compelling passages in Finnegan's book is one in which he describes the magnetic appeal of surfing as an adolescent, which resonates deeply with my own experience. It neatly goes some way to explaining the urge to write about surfing, to fill 'a psychic cavity of some kind', the sense of being 'privy to mysteries': 
I felt myself floating between two worlds. There was the ocean, effectively infinite, falling away forever to the horizon. This morning it was placid, its grip on me loose and languorous. But I was lashed to its moods now. The attachment felt limitless, irresistible. I no longer thought of waves being carved in celestial workshops. I was becoming more hard-headed. Now I knew they originated in distant storms, which moved, as it were, upon the face of the deep. But my utter absorption in surfing had no rational content. It simply compelled me; there was a deep mine of beauty and wonder in it. Beyond that, I could not explain why I did it. I knew vaguely that it filled a psychic cavity of some kind connected, perhaps, with leaving the church, or with, more likely, the slow drift away from my family - and that it had replaced many things that came before it. I was a sunburnt pagan now. I felt privy to mysteries. The other world was land: everything that was not surfing. Books, girls, school, my family and friends who did not surf. Society, as I was learning to call it. The exactions of Mr Responsible. (Finnegan, 2016)

The inscription in Finnegan's memoir - taken from Edward St. Aubyn's Mother's Milk (2006) - also speaks to the appeal of surf writing, offering that rarest of opportunities to let our writing follow the same intuitive, instinctive, fluid and flowing path as the surfer on the wave: 'He had become so caught up in building sentences that he had almost forgotten the barbaric days when thinking was like a splash of colour landing on a page' (Finnegan, 2016).

Surf writing, like the activity itself, inevitably brings us to the outer reaches of our abilities, poses a challenge that offers a never-ending journey toward mastery, while offering a childlike sense of pure play. Surfing and surf writing has, until now, allowed me to resist the demands of Mr Responsible, to occasionally forego the mere building of sentences, to savour the splash of colour landing on the page.

\section{Works cited}

Baker, T. (1997) Re-birthing a Legend. Inside Sport (April), page numbers unavailable.

Baker, T. (2005). Introduction: A brief history of surf writing. In T. Baker (Ed.) Waves: Great Stories From the Surf (pp. VII-XXII). Harper Collins.

Boddam-Whetman, J. (1876). Pearls of the Pacific. Hurst and Blackett.

Capp, F. (2003). That Oceanic Feeling. Allen \& Unwin.

Cook, J. (1784). A voyage to the Pacific Ocean: undertaken, by the command of His Majesty, for making discoveries in the northern hemisphere...: performed under the direction of Captains Cook, Clerke, and Gore, in His Majesty's ships the Resolution and Discovery: in the years 1776, 1777, 1778, 1779, and 1780. Printed by W. and A. Strahan for G. Nicol ... and T. Cadell. Available at http://nla.gov.au/nla.obj-53430374

Finnegan, W. (2016). Barbarian Days. Little Brown. Kindle edition. 
Finney, B.R. (1959). Surfing In Ancient Hawaii. Journal of the Polynesian Society 8(4), pp. 327-347.

Healy, C. (1915). The Referee. Sydney. 16 February, p. 1.

London, J. (1911) The Cruise of the Snark, Macmillan.

Maxwell, C. B. (1949). Surf: Australians against the sea. Angus and Robertson.

McTavish, B. (1967). Ladies and Gentlemen and Children of the Sun. Surf International. 1(2), Dec 1967 / Jan 1968. p. 9.

Melville, H. (1964 [1849]). Mardi and a Voyage Thither. Capricorn Books.

Pukui, M. K. (Translator) (2008 [1983]). Hawaiian Proverbs and Poetical Sayings (1983). In P. Moser, (Ed.) Pacific Passages: An Anthology of Surf Writing (pp. 47-48). University of Hawai'i Press.

Quote Investigator (2010). Writing About Music is Like Dancing About Architecture. Quote Investigator (8 November). https://quoteinvestigator.com/2010/11/08/writing-about-music/

Slattery, R. (1966). Wild Water. Horwitz.

Steedman, C. (1867). Manual of swimming: including bathing, plunging, diving, floating, scientific swimming, training, drowning, and rescuing. Henry Tolman Dwight / Lockwood \& Co. Available at https://catalogue.nla.gov.au/Record/2623027

Thompson, H. S. (2003 [1979]). The Great Shark Hunt: Strange Tales from a Strange Time. Simon \& Schuster Paperbacks, p. 530.

Twain, M. (1872). Roughing It. American Publishing Company.

Winton, T. (2008). Breath. Penguin.

Wise, H. E. (1850). Los Gringoes: or An Inside view of Mexico and California with wandering in Peru, Chile and Polynesia. Baker \& Scribner.

Wright, J. (1945). The Surfer. The Bulletin 66(3397), p. 4. 